mouth, and confirmed the laboratory tests, although some improvements in the anchoring of the synthetic fibre "pony-tails" were made.

Several overseas projects are being investigated. One of the most important must be the construction of two major dams on the Orange River, South Africa, as part of the large scheme to provide hydro-electric power and water for irrigation. The station has continued and extended its tests on models of the Van der Kloof and the Hendrik Verwoerd dams. Work on the Van der Kloof dam now includes investigations into erosion of the river bed some $500 \mathrm{ft}$. downstream of the dam face. The aim of tests is to find the most satisfactory method of armouring the alluvium in order to prevent exposure of the shale; and to determine the minimum size of armouring material required and, if possible, to demonstrate a practical method of placing the armouring. The report also discusses an analysis being made of the benefits the station brings to the economy and quotes examples based on investigations completed during recent years. Initial capital savings of approximately $£ 1.25$ million have been reported in connexion with construction of three new bridges for motorway and trunkroad crossings of riverflood plains, and a saving of $£ 2$ million resulted from a decision not to build a proposed new training wall for the entrance to a port after it was found that it would not produce the improvements required. The saving of $\mathfrak{f} 3.25$ million on these four projects, the report says, has more than paid the whole cost to public funds of setting up and running the laboratory.

Receipts for 1966 totalled over $£ 300,000$. The cost of running the laboratory was $\$ 482,000$ inclusive of interest on capital employed and depreciation of buildings and plant.

\section{More Reliable Pesticides}

A RECENT report by the World Health Organization (Specifications for Pesticides, WHO, £2) continues the work, begun in 1953, of specifying the quality control procedures for assessing the condition of pesticides. The present volume includes specifications for all pesticides currently in widespread use in public health programmes.

Pesticides are liable to deteriorate during transit and storage, especially in the harsh conditions of the areas where they are most used. Not only the active ingredient itself but the physical properties of the pesticide, such as its suspensibility in water, may also be impaired. The specifications drawn up by the WHO Expert Committee enable users and manufacturers to test the quality and durability of commercial pesticides.

As the report points out, the standards to which a pesticide is produced are a compromise between what the manufacturer can make, what the user wants, and what he is prepared to pay for it. It is therefore necessary that both manufacturer and user know for what purpose a pesticide is required, how it is to be used and what abnormal conditions of storage may have to be met.

Estimates that up to a third of world food production is destroyed by pests, and mounting evidence of the damage that can be caused by the unselective application of pesticides, are compelling motives for a more precisely controlled use of toxic chemicals. The WHO report is a valuable step in this direction.

\section{European Biologists}

Brology is a very diverse and all-embracing subject and the task of establishing "equivalences" for university teaching is by no means easy. Indeed, the question arises as to whether it is really necessary for higher education to be systematically organized. A new report, How to Qualify as a "Biologist" in the Universities of Europe, by Jean Leclercq, professor of zoology at the Faculty of Agronomic Sciences, Gembloux, examines this problem. The report, which deals with the teaching of zoology and general biology at univer. sity level, is one of a series of publications called "Education in Europe" and published by the Council for Cultural Co-operation of the Council of Europe.

Of the eight European countries which Professor Leclercq has examined, Britain, he says, has the greatest academic freedom. The system in Belgium, on the other hand, is one of the most rigid operating in Europe and a great deal of importance is attached to the exact sciences-physics, chemistry, calculus and so on-in the basic training of biologists. Belgian teaching staff in universities and institutions possessing university status do, however, have complete control over the content of the courses. The situation in France is quite the reverse-the system seems to be less rigid but French teachers have less real freedom than their Belgian colleagues. There exists a Franco-Belgian cultural agreement, the object of which is to encourage future Belgian students with the qualifying diploma in science to proceed to the second-stage course in a French university or, alternatively, to permit French students with a certificate attesting that they have passed the qualifying examination for higher studies (SPCN) to proceed to take their licence in a Belgian university. In general, however, this equivalence agreement has produced disappointing results.

University entrance from the senior forms of secondary schools into universities in the Federal Republic of Germany is a fairly easy process and both the Diplom and Staatsexamen courses take five to seven years. On paper the German student is entirely free to choose the lecture-series which he wants to attend and, subject to certain restrictions, to draw up his own programme of work: considerable academic freedom also exists for the teachers. But, according to Professor Leclercq, the German system is ill-designed for the establishing of equivalences and needs to be thoroughly remodelled.

In the Scandinavian countries the university curriculum resembles the studies systems in the univer. sities of Germany and Britain and there is considerable academic freedom. The selection process for would-be biologists is very stiff and the number of young Finns hoping to go to university is very large. The syllabus for the first two years of the bachelor (FK) can be compared with that of the ordinary licence course in France, Belgium and other countries.

As Professor Leclercq points out in his gencral conclusions, "biology studies as carried out in the universities of eight European countries have precious few common characteristics". But he feels that the difficulty of defining equivalences should not prevent students from transferring from one system to another. 